\title{
Uma revisão da questão da garrafa PET da prova ENEM 2013+*
}

Ernani Vassoler Rodrigues ${ }^{1}$

UP - União de Professores

Vitória - ES

\section{Resumo}

Este texto é uma breve revisão a respeito de um fenômeno natural envolvendo conceitos de mecânica dos fluidos e também uma revisão de uma questão da prova do ENEM 2013.

Palavras-chave: Ensino de Física. Hidrostática.

\begin{abstract}
This text is a small review on a natural phenomenon concerning Fluid Mechanics concepts and also a review of a question in the Brazilian National High School Test (ENEM) 2013.
\end{abstract}

Keywords: Physics Education. Hydrostatics.

\section{Uma breve revisão teórica}

Se pegarmos uma garrafa PET, cheia d'água e vedada e nela fizermos três furos, em alturas diferentes, a água vaza? E se a garrafa estiver aberta?

\footnotetext{
${ }^{+}$A review of the plastic bottle question of ENEM 2013 test

* Recebido: novembro de 2013.

Aceito: dezembro de 2013.

${ }^{1}$ Colaborador do PPG - Ensino de Física da UFES.
} 
A pergunta acima lida com alguns princípios básicos relativos à Mecânica dos Fluidos: um deles é a relação entre pressão atmosférica e a pressão dentro do recipiente, com base em conceitos de Hidrostática; o outro é o escoamento da água pelos orifícios, com base em conceitos da Hidrodinâmica.

A coluna d'água na garrafa, esteja a tampa aberta ou fechada, mostra uma pressão variável no interior da mesma. Assim, pela presença da coluna d'água, temos a pressão cada vez maior quanto mais fundo se vai dentro da garrafa, pois maior é o peso da massa d'água sobre o ponto em análise. Para uma coluna de líquido de densidade uniforme, a pressão do líquido é proporcional à altura da coluna do mesmo, já a pressão total é essa mesma, acrescida da pressão atmosférica, aqui chamada de $p_{a t m}$ (JESUS; MACEDO JR, 2011, p. 1507; YOUNG et al., 2012, p. 367):

$$
p_{t o t}=p_{a t m}+\rho g z
$$

sendo $\rho$ a massa específica do líquido (no caso da questão proposta, água), $g$ é a aceleração da gravidade e $z$ é a altura da coluna de líquido, que pode ser chamada de profundidade da superfície do líquido até o ponto onde se quer calcular a pressão hidrostática (nota para o sinal positivo no termo direito da equação, sugerindo um referencial z positivo e orientado paralelamente à ação da gravidade). Essa equação da pressão hidrostática mostra que, dentro do líquido, há um gradiente de pressão crescente com a profundidade, conforme a Fig. 1.

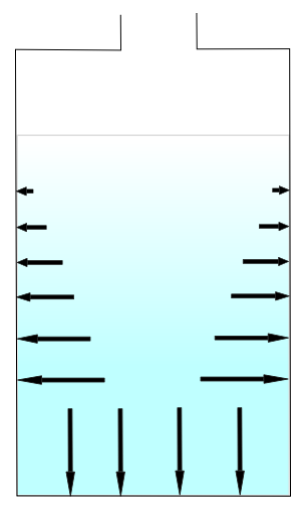

Fig. 1 - Gradiente de pressão, crescente com a profundidade, dentro de um líquido.

Já externamente ao líquido, a pressão atmosférica é constante (para pequenas variações de altitude como no caso da altura da garrafa) e é exercida em todas as superfícies que faceiam a atmosfera, conforme Fig. 2. 


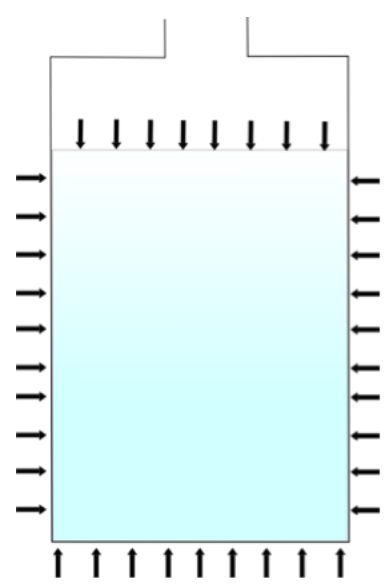

Fig. 2 - Pressão atmosférica, constante e em todas as interfaces do líquido e da superfície externa da garrafa com a atmosfera. A representação desta figura, correspondente ao caso da tampa aberta, deixando a superfície livre do líquido em contato com a atmosfera.

\section{Discutindo o caso da tampa fechada}

Com a garrafa cheia d'água e tampada, analisemos de que forma ocorreu o fechamento da garrafa considerando duas possibilidades:

\section{Possibilidade A}

Caso a garrafa esteja cheia d'água e inicialmente aberta, a pressão sobre a superfície do líquido é a pressão atmosférica. Tão logo a tampa seja colocada na garrafa, uma quantidade de ar será aprisionada sobre a superfície líquida e, então, a pressão sobre esta superfície, mesmo que com a tampa fechada, continuará sendo igual à pressão atmosférica. Com isso, qualquer ponto no interior da garrafa abaixo da superfície do líquido estará submetido a uma pressão maior que a pressão externa (atmosférica). Isso significa que, inicialmente, não haverá nenhum ponto no qual a pressão interna do líquido e a pressão externa do ar se equilibram, fazendo com que em um primeiro instante, a água vaze pelos três orifícios. Após um intervalo de tempo, esse vazamento faz com que o volume sobre a superfície do líquido, que inicialmente aprisionava uma quantidade de ar à pressão atmosférica, aumente, diminuindo a pressão sobre a superfície líquida, possibilitando que somente em um nível do líquido na garrafa as pressões do líquido da atmosfera se equilibrem. 


\section{Possibilidade B}

Se todo o ar da parte superior fosse retirado, pelo teorema de Stevin, é possível determinar que altura de coluna d'água permitiria equilíbrio neste caso, supondo que a garrafa não entrasse em colapso, conforme representa a Fig. 3.

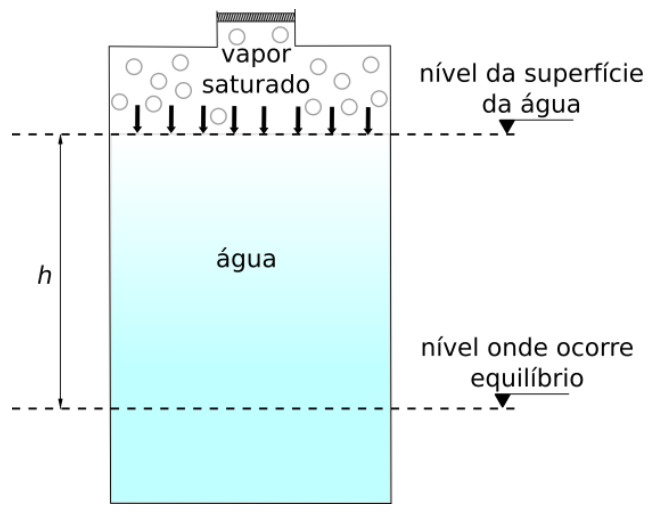

Fig. 3 - Representação da situação em que a garrafa tampada não possui nenhuma quantidade de ar aprisionada sobre a superfície. Sobre a superfície, há vapor saturado, devido à baixa de pressão.

Considerando, por exemplo, o valor da pressão atmosférica igual a $1,01 \times 10^{5} \mathrm{~Pa}$, a massa específica da água igual a $10^{3} \mathrm{~kg} / \mathrm{m}^{3}$, a aceleração da gravidade terrestre $g=10 \mathrm{~m} / \mathrm{s}^{2} \mathrm{e}$, ainda, a pressão de vapor da água à temperatura de $25^{\circ} \mathrm{C}$ igual a $3,16 \times 10^{3} \mathrm{~Pa}$, teríamos :

$$
\begin{gathered}
p_{a t m}=\rho g h+p_{v a p} \\
1,01 \times 10^{5}=10^{3} \times 9,80 \times h+3,16 \times 10^{3} \\
h \cong 9,98 \mathrm{~m}
\end{gathered}
$$

Nesta possibilidade, somente em uma garrafa PET com aproximadamente $10 \mathrm{~m}$ de altura e, ainda, se e somente se houvesse apenas um furo, na altura do nível representado na Fig. 3, poderia haver equilíbrio.

\footnotetext{
2 É necessário considerar a pressão de vapor da água, pois não havendo nenhum ar aprisionado sobre a superfície, a água será vaporizada por descompressão no topo da coluna.

${ }^{3}$ Valor calculado em <http://easycalculation.com/weather/water-vapor-pressure.php〉. Acesso em: 14 dez. 2013.
} 
De posse dessas informações, vemos que, se os três furos possuem alturas diferentes (em níveis diferentes do líquido), a pressão do líquido é diferente para cada um deles. Portanto, se em um deles a pressão do líquido equilibra a pressão da atmosfera, por este furo não haverá fluxo nem de líquido nem de ar. Mas, nos outros dois furos, isso não pode se repetir. Com isso, ocorrerá entrada de ar pelo furo onde a pressão externa é maior que a pressão do líquido, e saída de líquido pelo furo no qual a pressão interna seja maior que a externa. A oscilação no valor da pressão na superfície do líquido, com cada bolha de ar que entra por um dos furos, aumentando ligeiramente a pressão na superfície líquida, e com cada incremento de líquido que sai por outros furos, aumentando o volume da parte acima do líquido e com isso diminuindo ali a pressão, fará com que a água vaze de maneira intermitente pelo furo que está no nível intermediário.

\section{Discutindo o caso da tampa aberta}

Para a garrafa com a tampa aberta, teremos a pressão atmosférica sendo exercida na superfície do líquido, conforme a Fig. 2. A análise procede da mesma forma, porém, em todos os três furos, teremos a pressão do líquido somada à pressão atmosférica da superfície, o que será maior do que apenas a pressão atmosférica externa. Com isso, haverá vazamento de líquido pelos três furos.

Para se conhecer o mecanismo de escoamento, e assim fazer uma análise do fenômeno proposto, é necessário ter familiaridade com a equação de Bernoulli (YOUNG et al., 2012, p. 368; DORNELLES, 1996, p. 78), mostrada a seguir, na qual $v_{1}$ e $v_{2}$ são as velocidades de escoamento, respectivamente, na superfície do líquido dentro da garrafa e do fio de líquido que vaza pelo orifício:

$$
p_{a t m}+\rho g z_{1}+\frac{1}{2} \rho v_{1}^{2}=p_{a t m}+\rho g z_{2}+\frac{1}{2} \rho v_{2}^{2}
$$

Mesmo que limitada a situações específicas que apresentem escoamento não viscoso, é na equação de Bernoulli que justificamos a presença da pressão atmosférica em ambos os termos e, com isso, sua não influência na velocidade de escoamento, ficando esta como função da altura da coluna líquida.

Um vídeo da internet mostra o que acontece em cada um dos dois casos.

4 Disponível em: <http://www.youtube.com/watch?v=utIaOm1UseM\&feature=youtu.be〉. 


\section{Revisando a questão proposta pela prova do ENEM}

A prova do ENEM 2013 trouxe uma questão que discutia o vazamento de água por orifícios de uma garrafa pet, considerada ora tampada e ora destampada. O enunciado da questão propõe uma situação absurda, onde se afirma que, com a garrafa tampada, o líquido não sairá por nenhum dos três furos, além de um grave equívoco com relação às trajetórias dos fios d'água que vazam no caso da tampa aberta (SILVEIRA, 2013), somados à inadequação de objetos do conhecimento propostos para a prova e o que se pretende testar com as opções apresentadas.

Abaixo está o texto na íntegra, da questão proposta.

Para realizar um experimento com uma garrafa PET perfurou-se a lateral da garrafa em três posições a diferentes alturas. Com a garrafa tampada, a água não vazou por nenhum dos orifícios, e, com a garrafa destampada observouse o escoamento da água conforme ilustrado na figura:

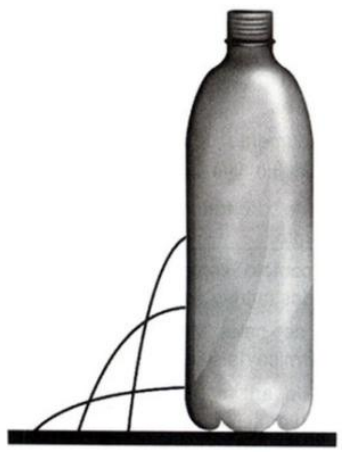

Como a pressão atmosférica interfere no escoamento da água nas situações com a garrafa tampada e destampada, respectivamente?

a) impede a saída de água, por ser maior que a pressão interna; não muda a velocidade de escoamento, que só depende da pressão da coluna de água.

b) impede a saída de água, por ser maior que a pressão interna; altera a velocidade de escoamento, que é proporcional à pressão atmosférica na altura do furo.

c) impede a entrada de ar, por ser menor que a pressão interna; altera a velocidade de escoamento, que é proporcional à pressão atmosférica na altura do furo.

d) impede a saída de água, por ser maior que a pressão interna; regula a velocidade de escoamento, que só depende da pressão atmosférica. 
e) impede a entrada de ar, por ser menor que a pressão interna; não muda a velocidade de escoamento, que só depende da pressão da coluna de água.

Fonte: prova do ENEM 2013, questão ${ }^{\circ} 59$, versão rosa ${ }^{5}$.

Pelo já exposto acima, vemos que a afirmação de não vazamento d'água com a tampa fechada é absurda. A experiência, apresentada no vídeo anteriormente indicado, igualmente demonstra que a suposição de o líquido não vazar é absurda.

No caso da garrafa destampada, a água também vazará. Porém a crítica agora está na figura escolhida - veja Silveira (2013) - e também na escolha da situação que a questão quer discutir. A lista de objetos do conhecimento proposta pelo MEC (2013) não contempla a discussão a respeito da dinâmica dos fluidos e da velocidade de escoamento. Encontram-se na literatura algumas propostas de discussão de fenômenos de hidrodinâmica para a sala de aula (DORNELLES, 1996; LOPES, 2010; JESUS; MACEDO JR, 2011), mas a discussão da velocidade de escoamento de um fluido foge ao escopo da prova proposta pelo MEC.

\section{Considerações finais}

Os argumentos apresentados nas seções anteriores demonstram cabalmente que a questão apresentada em uma prova de abrangência nacional e de grande importância contém inconsistências, propondo uma situação impossível, seja do ponto de vista da Mecânica de Fluidos, seja do ponto de vista experimental, pois a água vazará da garrafa com três furos abertos.

A matriz de habilidades do ENEM (MEC, 2013,p. 1) é fundamentada em cinco eixos cognitivos. Destaque para o eixo cognitivo II:

Compreender fenômenos $(\boldsymbol{C F})$ : construir e aplicar conceitos das várias áreas do conhecimento para a compreensão de fenômenos naturais, de processos histórico-geográficos, da produção tecnológica e das manifestações artísticas.

Além disso, os Parâmetros Curriculares Nacionais estipulam por lei em seu Artigo $9^{\circ}$ que a escola deve contextualizar o estudo de ciências. Atentemos ao que diz (PCN, 2000: Art. $9^{\circ}$, item II; p105-g):

Apropriar-se dos conhecimentos da Física, da Química e da Biologia e aplicar esses conhecimentos para explicar o funcionamento do mundo natural, planejar, executar e avaliar ações de intervenção na realidade natural.

${ }^{5}$ Fotocopiada e disponível em: <http://noticias.terra.com.br/educacao/enem/>.

Caderno Brasileiro de Ensino de Física, v. 31, n. 2, p. 421-428, ago. 2014. 
O MEC divulgou o gabarito oficial da prova ENEM $2013^{6}$ e não considerou a anulação deste item discutido acima.

A aparição desse tipo de equívoco fenomenológico sugere que o processo de elaboração de tais questões deve ter um crivo de revisões mais cuidadoso, evitando distorções.

Equívocos são inerentes a atividades complexas intelectualmente, como elaborar uma prova de ciências da natureza, pautada em conceitos coerentes, do ponto de vista do pensamento científico em detrimento ao senso comum. Assim, tais equívocos podem ser um problema de fácil solução como, por exemplo, a anulação do item. Revisões como esta almejam que professores de Física no país inteiro possam debater questões, confrontar versões da ciência para fenômenos naturais e aprimorar a forma de lidar com a problematização de situações do mundo real, repensando, revisando e refinando conceitos em uma busca intensa e constante de uma educação em ciências cada vez mais aprimorada.

\section{Referências Bibliográficas}

DORNElleS, A. A. F. Uma questão em hidrodinâmica. Caderno Catarinense de Ensino de Física, v. 13, p. 76, 1996.

JESUS, V. L. B.; MACEDO JR., M. A. V. Uma discussão sobre hidrodinâmica utilizando garrafas PET. Revista Brasileira de Ensino de Física, v. 33, p. 1507, 2011.

LOPES, W. Velocidade de escoamento horizontal de água por um conduto. Caderno Catarinense de Ensino de Física, v. 27, p. 385, 2010.

MEC - Ministério da Educação do Brasil. Matriz de Habilidades do ENEM 2013. Disponível em: <http://portal.mec.gov.br/>. Acesso em 28 out. 2013.

PCN - Parâmetros Curriculares Nacionais 2000. Disponível em: <http://portal.mec.gov.br/seb/arquivos/pdf/blegais.pdf>. Acesso em 28 out. 2013.

SILVEIRA, F. L. INFORMES: CREF-IFUFRGS. Caderno Brasileiro de Ensino de Física, v. 30, p. 659, 2013.

YOUNG, H. D.; FREEDMAN, R. A.; FORD, A. L. Sears and Zemansky's University Physics: with Modern Physics. 13 ed. San Francisco: Pearson, 2012.

${ }^{6}$ Disponível em: <http://enem.inep.gov.br/>. Acesso em: 01 nov. 2013. 